\title{
Dual Approach to Portal and Superior Mesenteric Vein Thrombosis in an Octogenarian Patient
}

\author{
Muhammed Raşid Aykota ${ }^{1}$, Mustafa Atabey ${ }^{2}$ and Ali Kağan Gökakın ${ }^{3 *}$ \\ ${ }^{1}$ Department of General Surgery, Turkey \\ ${ }^{2}$ Medicana International Hospital, Turkey \\ ${ }^{3}$ Department of General Surgery, Turkey \\ *Corresponding author: Ali Kağan Gökakın, Department of General Surgery, Turkey

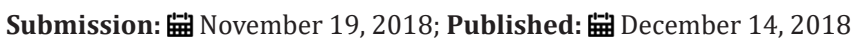

\begin{abstract}
Mesenteric venous thrombosis (MVT) is an uncommon catastrophic form of mesenteric vascular occlusion. This clinical entity is associated with severe and potentially lethal complications. It accounts for 5-15\% of the acute causes of mesenteric ischemia and up to $20 \%$ of all cases of intestinal infarction. In the literature, successful non-operative treatment options of MVT such as thrombolytic infusion via the superior mesenteric artery (SMA) or directly into the portal (PV) or superior mesenteric veins (SMV) via the transjugular or transhepatic routes have been shown. However; only a limited number of reports has pointed out thrombolysis by using a jejunal mesenteric vein. Here, the case of a patient with acute PVT and MVT, having a history of oral contraceptive usage who was treated successfully with limited bowel resection and thrombolytic infusion via a jejunal vein, is reported.
\end{abstract}

Keywords: Portal and mesenteric vein thrombosis; Thrombolysis; TPA; Oral contraceptives

\section{Introduction}

Mesenteric venous thrombosis (MVT) is an uncommon catastrophic form of mesenteric vascular occlusion. This clinical entity is associated with severe and potentially lethal complications $[1,2]$. It accounts for $5-15 \%$ of the acute causes of mesenteric ischemia [3], and up to $20 \%$ of all cases of intestinal infarction [4]. In the literature, successful non-operative treatment options of MVT such as thrombolytic infusion via the superior mesenteric artery (SMA) or directly into the portal (PV) or superior mesenteric veins (SMV) via the transjugular or transhepatic routes have been shown [5-8]. However; only a few reports have pointed out thrombolysis by using a jejunal mesenteric vein. Here, the case of a patient with acute PVT and MVT, having a history of oral contraceptive usage who was treated successfully with limited bowel resection and thrombolytic infusion via a jejunal vein, is reported.

\section{Case Report}

An 85-year-old woman was referred to our clinic from the department of gastroenterology, who had a 3-day history of severe constant epigastric pain with sudden onset. Neither protein $\mathrm{C}$ activity nor protein $\mathrm{S}$ activity was decreased in the evaluation of hypercoagulability. The use of oral contraceptives for five years 40 years ago was stated by the patient. Acute abdominal signs of abdominal distension with diminished bowel sounds and rebound tenderness were detected in physical examination. Prothrombin time (PT), international normalized ratio (INR), activated partial thromboplastin time (aPTT) levels, and blood chemistry were in normal range; however, WBC and CRP levels were elevated. General intraperitoneal free fluid, thrombosis of the PV (main trunk and two main branches), SMV, and splenic vein with a thickened small bowel wall were revealed via Abdominal Computed tomography (CT) (Figure 1).

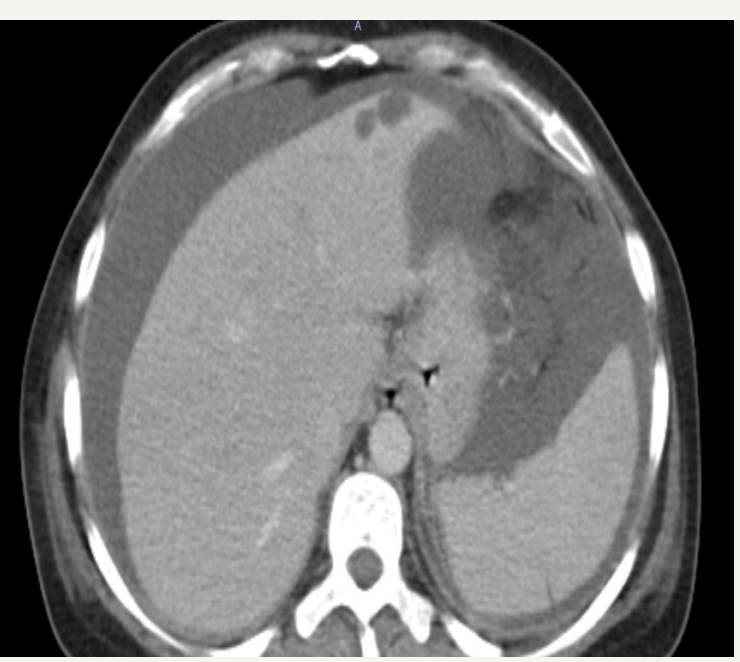

Figure 1(A): Generalized intraperitoneal free fluid. 


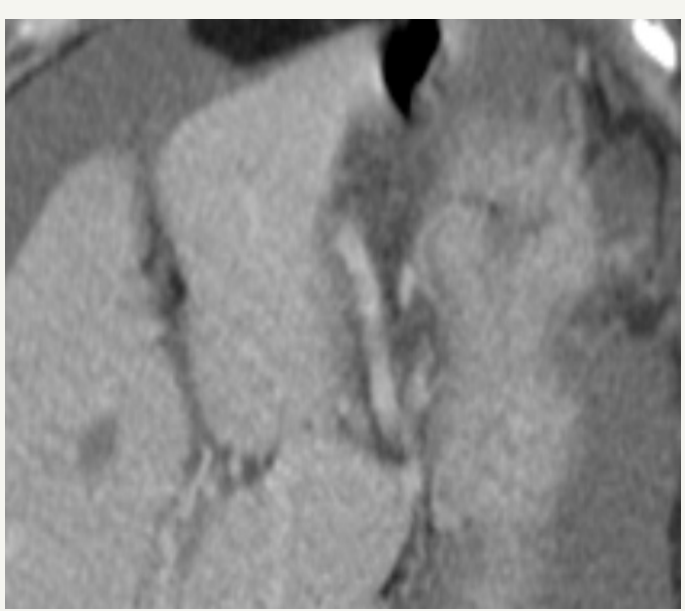

Figure 1(B): Thrombosis of the PV (main trunk and two main branches), SMV, and the splenic vein.

A bolus dose of $5000 \mathrm{U}$ heparin treatment followed by a continuous infusion of $1000 \mathrm{U} / \mathrm{h}$ was preoperatively given at the operating theatre. A thickened small bowel, thrombosed lineal vein with a normal-size spleen and edematous mesentery with hard and thrombosed jejunal veins, and about 2000cc free peritoneal fluid were detected in the examination. $A 80 \mathrm{~cm}$ jejunal segment was resected due to infarction, and an end-jejunostomy and jejunal mucous fistula were performed. After the puncture of the balloon, a $3 \mathrm{~F}$ Fogarty-catheter was inserted and positioned at the confluence of the SMV and splenic vein under fluoroscopic guidance. Angiography performed by the catheter identified no image of the SMV, PV, and the splenic vein (Figure 2). The other end of the catheter was forwarded through the abdominal wall, and $50 \mathrm{mg}$ alteplase corresponding 29,000,000 UI (ACTILYSE®50mg flacon) was administered. A temporary abdominal closure was done in preparation for the planned second-look operation.

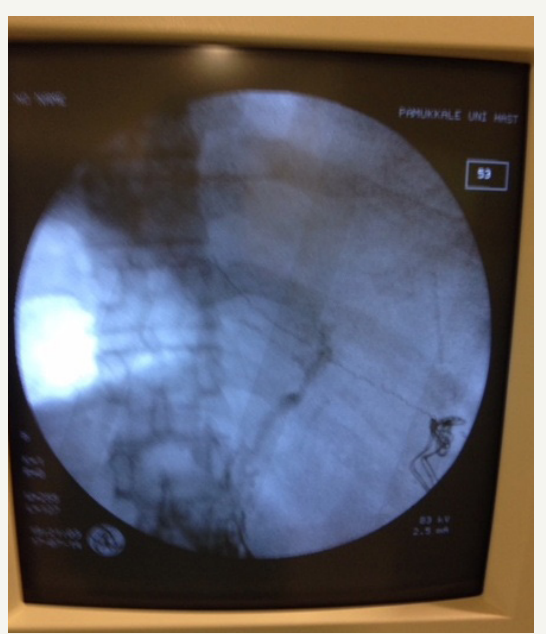

Figure 2: Angiographyviathe catheter has identified no image of the SMV, PV, and the splenic vein.

On the next day, an additional 50mg d'altéplase bolus dose was given via a jejunal vein catheter and the heparin was titrated postoperatively according to the aPTT measurements. The patient was returned to the operating theatre for a second-look procedure $36 \mathrm{~h}$ after the first operation. All the jejunal segments were viable and complete resolution of the SMV thrombosis and partial resolution of PV were detected in the postop angiography (Figure 3). Splenic vein was still thrombosed, but the spleen had a normal shape and size. Following an end-to-end anastomosis, the catheter was removed, and the abdomen was closed. The heparin infusion was stopped on the 10thday of the second-look operation. The patient was discharged on the $14^{\text {th }}$ postoperative day. She is still under follow-up and in a good health 5 years after the surgery.

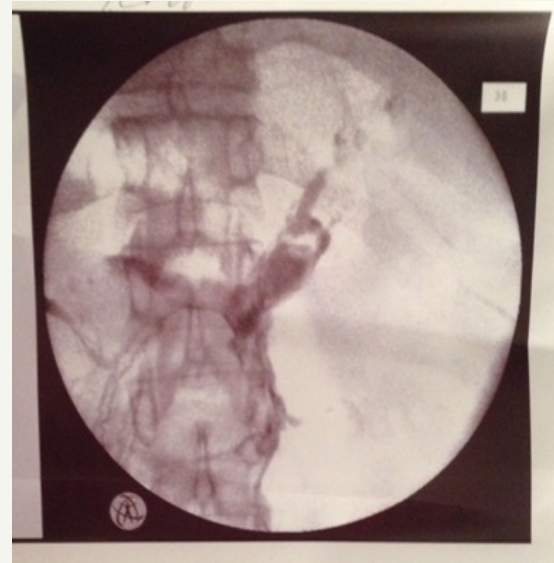

Figure 3: Complete resolution of the SMV thrombosis and partial resolution of PV were detected in the postoperative angiography.

\section{Discussion}

Development of thrombus in the portal vein and/or its left or right branches is known as acute portal vein thrombosis. Intestinal infarction may occur when it extends to the mesenteric venous arches with a reported mortality of up to 50\% [9]. Miscellaneous etiological factors have been argued for portal vein thrombosis. In patients without cirrhosis; a prior history of abdominal surgery, pancreaticobiliary disease, alimentary tract disease, and a prothrombotic mutation including protein $\mathrm{C}$ deficiency, factor $\mathrm{V}$ Leiden, methylenetetrahydrofolate reductase gene mutation, prothrombin gene mutation can be the most common reasons of PVT. Furthermore, trauma and the use of oral contraceptives are also shown to be the etiological factors for PVT and MVT [10]. The use of oral contraceptives was the only risk factor in the present case. Abdominal CT has demonstrated the pathology in the patient and CT has been reported as the most sensitive diagnostic tool for acute PVT and MVT [1]. Conservative medical treatment is often unsatisfactory. Surgical treatment is the choice of the treatment when acute abdomen is apparent, even it is accompanied by tissue damage, complications, and a high recurrence rate [2].

\section{References}

1. Ozdogan M, Gurer A, Gokakin AK, Kulacoglu H, Aydin R (2006) Thrombolysis via an operatively placed mesenteric catheter for portal and superior mesenteric vein thrombosis: Report of a case. Surg Today 36(9): 846-848. 
2. Loss M, Lang SA, Uller W, Wohlgemuth WA, Schlitt HJ (2014) Combined surgical and interventional therapy of acute portal vein thrombosis without cirrhosis: a new effective hybrid approach for recanalization of the portal venous system. J Am Coll Surg 218(3): e79-e86.

3. Rhee RY, Gloviczki P (1997) Mesenteric venous thrombosis. Surg Clin North Am 77(2): 327-338.

4. Ellis DJ, Brandt LJ (1994) Mesenteric venous thrombosis. Gastroenterologist 2: 293-298.

5. Wang Y, Wang MQ, Liu FY, Wang ZJ, Duane F, et al. (2012) Transracial approach for transcatheter selective superior mesenteric artery urokinase infusion therapy in patients with acute extensive portal and superior mesenteric vein thrombosis. Zhonghua Yi Xue Za Zhi 92(21): 1448-1452.

6. Henio EA, Bohannon WT, Silva MB (2003) Treatment of portal venous thrombosis with selective superior mesenteric artery infusion of recombinant tissue plasminogen activator. J Vasc Surg 38(6): 14111415.
7. Lopera JE, Correa G, Brazin A, Ustinov B, Patel S, et al. (2002) Percutaneous transhepatic treatment of symptomatic mesenteric venous thrombosis. J Vasc Surg 36(5): 1058-1061.

8. Sze D, O'Sullivan GJ, Johnson DL, Dake MD (2000) Mesenteric and portal venous thrombosis treated by transjugular mesenteric thrombolysis. Am J Roentgenol 175(3): 732-734.

9. Kumar S, Kamath PS (2003) Acute superior mesenteric venous thrombosis: one disease or two? Am J Gastroenterol 98(6): 1299-1304.

10. Chen C (2012) Direct thrombolytic therapy in portal and mesenteric vein thrombosis. J Vasc Surg 56(4): 1124-1126.
Creative Commons Attribution 4.0

International License

For possible submissions Click Here

\section{Submit Article}

GGS | Gerontology \&

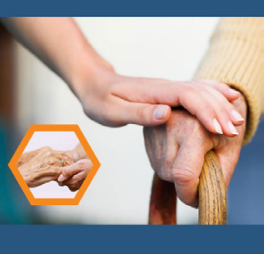

\section{Benefits of Publishing with us}

- High-level peer review and editorial services

- Freely accessible online immediately upon publication

- Authors retain the copyright to their work

- Licensing it under a Creative Commons license

- Visibility through different online platforms 